\title{
CURRICULUM ANALYSIS OF PERMAI PLUS SCHOOL AT PLUIT'S ELEMENTARY CHINESE COURSE

\author{
分析珊瑚新村的培迈三语学校的小学汉语课程
}

\author{
Yetty \\ Chinese Department, Faculty of Language and Culture, Bina Nusantara University, \\ Jl Kemanggisan Ilir III No. 45, Kemanggisan/Palmerah, Jakarta Barat 11480
}

\begin{abstract}
In Indonesia, in addition to english mandarin also become a very common thing. Many companies employ one of the conditions of staff must be fluent in speaking Chinese, reading and writing Chinese characters. Therefore, the majority of schools in Indonesia have set up Chinese language courses, in order to give Chinese language's basic foundation to their students. In Pluit, courses of Chinese language schools are mostly private, three-language schools and international schools (not including international schools in the U.S. system). Through the six factors of curriculum (Teachers, facilities, scores, textbooks, curricula, and social participation ), the writer wants to analyze Permai Plus school curriculum Chinese course situation.
\end{abstract}

Keywords: Chinese, curriculum, primary school

\section{内容摘要}

在印尼除了英语以外, 汉语现在也很普遍了。不少企业聘请职员的条件之一是必须会讲一口流利的 汉语、会读写汉字。因此目前印尼的学校大多数有汉语课程设置, 这是为了打好学生的汉语基础。在珊 瑚新村有汉语课程设置的学校大部分是私立学校、三语学校和国际学校 (不包括美国体制的国际学校) 。笔者通过课程设置的六个因素 (教师、设施、评分、教科书、教学大纲和社会参) 想分析培迈三语学 校的小学汉语课程设置情况

关键词: 汉语、课程设置、小学 


\section{前言}

目前，中国是世界上经济发展最快的国家之一。汉语已经成为联合国的官方语言之一。现 在在印尼, 汉语扮演很大的角色, 因为目前在印尼有很多中资台资企业, 所以汉语成为必须掌 握的语言之一。因此老老少少都开始学习汉语, 不只是印尼华侨, 连印尼原住民也开始学习汉 语了。

从 2000 年开始, 印尼人民可以自由地学习汉语。不少大学也开设了中文系, 许多学校都 开设了汉语课程, 汉语补习班纷纷建立。他们使用的教学体制大都是中国或新加坡的汉语课程

在一所学校, 课程设置是学校其中最重要的一部分。课程设置的主要因素是教师、设施、 评分、教科书、教学大纲和社会参与。

教师要知道怎样监督学生的学习活动、推动学生的积极性、教导和监视学生的态度、制造 和提供教学方案、教导与作为学生的学友。为了创造良好的教学气氛, 学校必须提供足够的设 施, 如教室、桌椅、办公室、多媒体教室、图书馆等。评分包括考试, 练习, 作业, 集体合作 等方面。评分的目的是为了了解学生们对课目的掌握。学校使用的教科书是根据学校的课程设 置。教学大纲包括课时、教学过程、教学步骤、教学工具与教材。社会参与分成两类, 就是参 观和比赛活动。这些活动是希望学生通过参观和比赛活动能挖掘他们的语言能力, 学生能了解 学习外语的意义, 功能和作用。

三语学校使用的课程设置是国民课程与国际课程的混合, 课堂上使用语是英文或中文。培 迈三语学校使用新加坡课程设置。为了解三语学校的汉语课程设置情况, 笔者对培迈三语学校 进行了调查。

\section{内容}

\section{一、语言与现代汉语的概述}

(一) 语言的定义

语言是所有正常的人类都具有的讲话的能力。不同地区之间人类所使用的语言千差万 別, 但是任何人都必須通过学习才能获得语言能力。对于这个非常复杂、重要的概念, 语 言是很难清楚定义的。然而大部分人都会同意, 语言是一套通过表示方法和合乎逻辑的语 法构成的进行沟通和推理的系统。许多语言通过手势、声音、符号和文字來传递, 目的是 交流观念、意见、思想和含义等。下列有语言的一些作用 ${ }^{1}$ :

(1) 引进和搜寻实际的信息

（2）表达和判决智力

（3）表达和判决情绪

（4）表达和判决道德

(5) 解决矛盾 (说服)

（6）交际

\footnotetext{
${ }^{1}$ 《基础语言学教程》, 叙通铭, 北京大学出版社, 2001 年 2 月 1 版
} 


\section{（二）汉语的定义}

汉语是汉民族的语言，现代汉语是现代汉民族所使用的语言。现代汉语共同语就是以 北京语音为标准音, 已北方话为基础方言, 以典范的现代白话文著作为语法规范的普通话。 普通话是现代汉语民族重要的交际工具也是国家法定的全国通用语言。汉语作为一种语言, 具有一切语言共同的属性。从结构上说, 它是一种音义结合的符号系统。从功能上说, 它 是人们最重要的交际工具和思维工具, 部分阶级一视同仁地为汉民全体成员服务 ${ }^{2}$ 。

\section{二、课程的概述}

\section{(一) 课程的定义}

课程是教育中最重要、最繁难、最易被误解的问题之一。课程是关于教育目标、内容、 方法和评价的一个系统, 是教育思想, 教育论转化为教育实践的中介或桥梁, 教育实践常 以课程为轴心展开, 教育改革也常以课程改革为突破口而进行。

课程 “广义指所有学科（教学科目）的总和。或指学生在教师指导下各种活动的总和。 狭义指一门学科” ${ }^{3}$ 。1987 年版的《辞海》 (新二版) 也有类似的情况, 对 1980 年版的定 义作了一些修改, 保留了将课程定义为学科的部分, 也指出课程 “广义指学校中学习活动 的范围和进程”

在实用语言学领域里, 理查德、普莱特与普莱特 (Richards, Platt and Platt) 在 朗文实用语言学词典（1992 年，94 页）里认为, 课程应具备的三个要件:

1. 制定教学目标

2. 通过内容、教学程序和学习经验达到教学目标

3. 评价教学目的是否已经达到了。

(一) 影响课程的因素

课程设置是否有效必须符合几个因素，就是教师、设施、评分、教科书、教学大纲和 社会参与。

1. 教师

教师是人类文明的传递者。教师这一职业, 是人类社会最古老的职业之一。纵观社会 发展的历史, 就会发现教师是伴随学校教育的产生而出现的。在人类社会的分工中, 教师自始至终担负着传播人类文化知识的重要社会职能 5 。他指担任教学工作的专业人 员。

不论课程和教学大纲有多么完善, 课程和教学大纲的成功都要看教师在课堂上怎样运

用, 因为教师能直接与学生沟通。教师的作用是:

- 监督学生的学习活动。了解学生的学习方法、做学生学习过程的桥梁。

- 提高学生的积极性。教师应鼓励学生, 帮助学生建立信心。因为学生的成就是建 立在他是否有信心能掌握教师所教的内容。

- 教导和监督学生的学习。教师应该鼓励学生让他们有勇气使用外语。

- 制造与提供教学方案。为了创造好的学习气氛, 教师必须有创造性, 这能使学生 不知不觉地使用外语。

- 与学生做朋友。教师应该给予学生鼓励与表扬。

\footnotetext{
2 《现代汉语》上册, 黄伯荣, 高等教育出版社, 2002 年 7 月 3 版

${ }^{3}$ 《中国大百科全书》（教育学），中国大百科全书出版社 1985 年版，第 207 页

${ }^{4}$ 《辞海》（教育、心理分册），上海辞书出版社 1987 年版，第 13 页

${ }^{5}$ 《普通教育学》, 许高厚, 北京师范大学出版社, 1995 年 8 月 1 版
} 
2. 设施

外语教育课程必须具备足够的设施，包括教室、桌椅、办公室、多媒体教室、图书馆 等。

3. 评价

艾德温 · 冯特 (Edwin Wandt) 与格兰尔德 - 韦 . 布朗（Gerald W. Brown）（1977） 认为：评价是指评价某件事的分数的措施。在学校, 学生的分数是通过考试、练习、 作业、集体合作等评价的。这些评价是为了了解学生们对课目的了解。

4. 教科书

教科书又称课本, 或称教材, 是根据教学大纲系统表述学科内容的教学用书, 是教学 大纲的具体化。教科书一般包括: 目录、课文、习题、练习、实验、图表、注释、附 录、索引等。课文是教科书的基本部分 ${ }^{6}$ 。

联合国教育科学及文化组织（UNESCO）制定教科书必备三个主要作用（塞甘（Seguin） 1989 年: 18-19 页） :

- 信息作用

- 安排与组织学习作用

- 指导学生学习作用

5. 教学大纲

教学大纲又称课程标准, 是以纲要的形式规定有关学科内容的指导性文件。各门学科 的目的、任务、内容、范围、体系、教学进度与时间以及教学方法上的具体要求都规 定在教学大纲中。教学大纲的结构一般分为说明和本文两个部分 ${ }^{7}$ :

- 说明十分简要地叙述这一学科在学校中讲授的目的、任务、指出教材编选的主要 依据以及教学法上的原则要求。

- 大纲的基本部分是本文。本文系统地规定教材的全部主要课题及教学时数, 每个 课题内容的要点以及实验、实习和其他作业等。

6. 社会参与

通过参观和比赛活动, 希望学生能了解学习外语的意义, 功能和作用, 提高他们的语 言能力。

参观是根据教学需要, 教师组织和带领学生到校外一定的场所, 对实际事物进行观察 研究, 从而获得知识或巩固、验证已学知识的方法。参观能有效使学生把书本知识与 社会产与生活实际结合起来, 帮助学生更好地领会和掌握知识; 它可以扩大学生的眼 界，激发学生的求知欲; 还可以使学生受到生动而实际的思想教育。

比赛是指一种竞争实力的活动。外语比赛一般有写作、讲故事、诗朗诵比赛等。

\section{三、 三语学校小学汉语课程的分析}

笔者想通过教师、设施、评价、教科书、教学大纲和社会参与这六个方面调查小学的汉语 课程设置情况。为此, 笔者采访了这所三语学校的教师。

笔者在二零零七年五月十五日采访了培迈三语学校的汉语教师温丽丽女士。培迈三语学校 位于珊瑚河西部路 0/ VI B 巷十六号成立于二零零四年七月五日。该校建校开始就有了汉语 课。共有汉语教师三位, 学生共 94 名。

\footnotetext{
${ }^{6}$ 《普通教育学》, 许高厚, 北京师范大学出版社, 1995 年 8 月 1 版

${ }^{7}$ 《教育学》, 传道春, 高等教育出版社, 2000 年 5 月 1 版

${ }^{8}$ 《教育学》, 传道春, 高等教育出版社, 2000 年 5 月 1 版
} 
下面, 笔者根据影响课程的六个主要因素: 教师、设施、评价、教科书、教学大纲与社会 参与对培迈三语学校的小学汉语课程设置分析, 希望从这六个因素中能了解三语学校的小学汉 语课程设置分析。

\begin{tabular}{|c|c|}
\hline 必备条件 学校 & 培迈三语学校 \\
\hline 国籍 & 中国、印尼 \\
\hline 学位 & 学士学位 \\
\hline 专业 & 任何专业 \\
\hline 教师资格证 & 没有 \\
\hline 教学方案 & 有 \\
\hline 教学方法 & 积极, 有创造力 \\
\hline
\end{tabular}

培迈三语学校也有三位汉语教师，一位是中国教师, 其他两位是印尼华侨。培迈三语学校 选择教师时是根据学校的需求。该校的教师必须具有学士学位, 因为这是目前工作的条件之一, 教师的专业不一定要中文系, 最重要的是掌握汉语与能教好学生。目前印尼政府还没规定每个 教师必有教师资格证, 所以该校不要求教师必有教师资格证。培迈三语学校教师要懂英文因为 开会时使用英语。

培迈三语学校教师不需要做教学方案因学校已提供教学方案。培迈三语学校设计的教学方 案里只有教材、教学工具。教学方案不设计教学目的、教学步骤、教学过程、与课时。学校不 要求教师准备教学目的、教学步骤、教学过程与课时安排。该校教师的教学法积极、有创造力。

培迈三语学校一年级和二年级学生每个班大概 20 名, 三年级和四年级个班学生约 16 名。 这样教师比较容易控制教学质量, 学生较容易了解教师所讲的课。培迈三语学校的教师还能推 动学生学习的积极性、作为学生的学友。

表 2 设施

\begin{tabular}{lc}
\hline 学校 & 培迈三语学校 \\
\hline 设施 & \\
\hline 教室 & 有 \\
桌椅 & 有 \\
多媒体教室 & 有 \\
办公室 & 有 \\
图书馆 & 有 \\
\hline
\end{tabular}

该校的设施都比较完善，有办公室、图书馆和多媒体教室，教室里都配备舒适的桌椅并已 安装空调。图书馆里有寓言故事、漫画、电视、录音机、光盘（听力课教材）。培迈三语学校 没有中文电脑课的原因是因为校方不安排中文电脑课。

培迈三语学校的学生很积极, 原因是每天早上该校实行阅读活动, 教师带领学生到图书馆 看书。每星期一位学生至少必读一本汉语书。 
表 3 评分

\begin{tabular}{lc}
\hline 学校 & 培迈三语学校 \\
\hline 评分 & \\
\hline 考试 & 有 \\
练习 & 有 \\
作业 & 有 \\
集体合作 & 没有 \\
学生的积极性 & 有 \\
\hline
\end{tabular}

培迈三语学校的评分项目是考试、练习、作业与学生的积极性。学校的主要评分有两方面, 第一、期中考试（ $\mathrm{CA}=$ Continuous Assessment）一学期两次。第二、期末考试（SA $=$ Semesteral Assessment）一学期两次。第一次 CA 的评分占百分之十、第二次占百分之三十。 第一次 SA 的评分占百分之二十、第二次占百分之四十。学生至少得到百分之五十的评分才能 升班。若学生的成绩不及格, 教师就根据学生的练习、作业和积极性分数给予加分。这样能帮 助努力、认真但汉语水平却不好的学生。

表 4 教科书

\begin{tabular}{lc}
\hline 学校 & 培迈三语学校 \\
\hline 教科书 & 小学华文 \\
& 新加坡课程发展署 \\
\hline
\end{tabular}

培迈三语学校使用的教科书是小学华文 (新加坡课程发展署)。培迈三语学校使用的小学 华文教科书的原因是教科书是根据学校课程和内容符合学生的汉语水平。

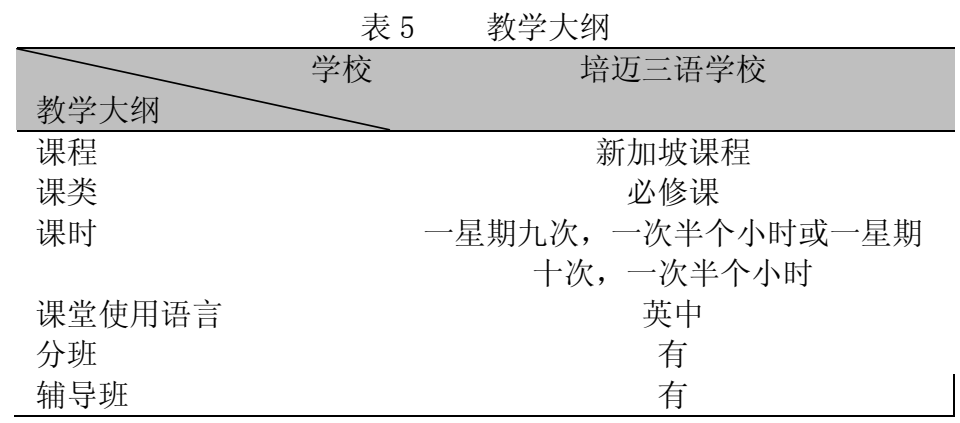

培迈三语学校使用新加坡的课程因为英文课也使用新加坡课程。该校只有在一年级时教师 很少使用中文授课, 原因并不是所有学生都有汉语基础, 二年级以上使用英中授课。教师与学 生的沟通基本上没问题。培迈三语学校的课程目的是让学生学好汉语、掌握好汉语。目前学校 的课程目的已经达到了。若学生掌握不好汉语, 该校采取的措施是教师讲课时会比较慢和比较 详细。培迈三语学校有分班, 汉语水平比较高的学生一星期上九次课, 水平较低的学生一星期 上十次课。

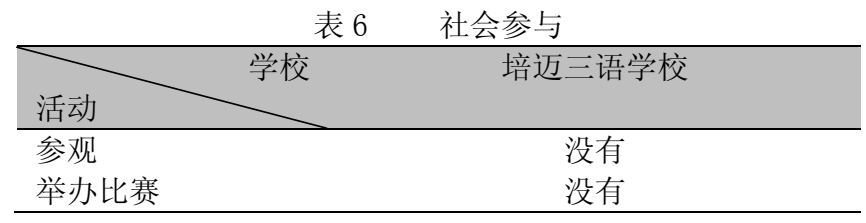


培迈三语学校都没有举办参观活动。培迈三语学校不举办参观活动的原因是因为学校认为 学生还太小。除此之外, 该校未举办过任何汉语比赛。培迈学校到目前为止不参加其他学校的 汉语比赛, 原因是学生的年纪太小。

\section{结论}

影响课程设置有六个因素, 就是教师、设施、评价、教科书、教学大纲和社会参与。笔者 根据这些因素来分析培迈三语学校的课程。

(一) 教师方面

1. 教师必须具有学士学位,

2. 教师必有教师资格证

3. 教师要懂英文

4. 教师的教学法积极、有创造力。

(二) 设施方面, 该校的设施都比较完善。

（三）评分机制方面，通过期中考试和期末考试两方面进行评分。

（四）教科书方面, 培迈三语学校使用新加坡课本《小学华文》, 这本教科书是根据学校课程 和内容符合学生的汉语水平。

(五) 教学大纲方面,

1. 汉语课是必修课

2. 使用新加坡课程系统

3. 课堂用语是英语和汉语

4. 按照学生的水平分半

5. 有辅导班。

(六) 社会参与方面, 学校都尚未举办过参观或比赛活动,

笔者通过课程设置这六个因素分析后得到得结论是：该校在设施、评分机制、教科书与教 学大纲方面已经很好，但是在教师的教学方法和社会参与方面还需要改进。

\section{参考文献}

Kushartanti,Lauder., M. R., Yuwono, U. (2005_. Pesona Bahasa: Langkah Awal memahami Linguistik. Jakarta: PT. GramediaPustakaUmum.

Richards, J. C. \& S. Rodgers, T. S. (2001).Approaches and methods in language teaching. Cambridge: Cambridge University Press.

Richards, J. C. \&Renandya, W. A.(2002). Methodology in Language Teaching: An Anthology of Current Practice.Cambridge: Cambridge University Press.

Santrock, J. W. (2008). Education Psychology Third Edition. New York: The McGraw-Hill Companies, Inc.

Santrock, J. W. (2001). Adolescence Eight Edition. New York: The McGraw-Hill Companies, Inc. 
Sudijono, A. (2001). Pengantar Evaluasi Pendidikan. Jakarta: PT RajaGrafindoPersada.

现代汉语, 《2002》, 上册, 黄伯荣, 高等教育出版社, 2002 年 7 月 3 版 幼儿园课程, 《2003》, 朱家雄, 华东师范大学出版社, 2003 年 6 月 1 版 基础语言学教程, 《2001》, 叙通铭, 北京大学出版社, 2001 年 2 月 1 版 教育学，《2000》，传道春，高等教育出版社， 2000 年 5 月 1 版 普通教育学，《1995》，许高厚，北京师范大学出版社，1995 年 8 月 1 版 